\title{
Percepçóes Sobre Pessoas com Deficiências e o Prognóstico para o Atendimento Educacional Especializado ${ }^{1}$ \\ Perceptions of Persons With Disability and Prognosis for SpeCIALISED EDUCATIONAL SERVICES
}

\author{
Everton Luiz de OLIVEIRA² \\ Enicéia Gonçalves MENDES ${ }^{3}$
}

\begin{abstract}
RESUMO: o presente estudo objetivou verificar se a atratividade física facial de alunos com deficiência auditiva poderia exercer influência nos prognósticos feitos por professores que atuam no atendimento educacional especializado - Salas de Recursos Multifuncionais (SRMs). Foram selecionados 20 professores que atuam em SRMs em um município do interior do estado de São Paulo. Os participantes realizaram uma atividade envolvendo a previsão de resultados para o atendimento educacional especializado de alunos com deficiência auditiva. Como estímulos utilizaram-se fotografias de crianças, de ambos os sexos, com diferentes níveis de atratividade física. Os prognósticos favoráveis para o atendimento especializado recaíram mais frequentemente sobre os alunos com alta atratividade física. Contudo, apenas para as fotografias das meninas foi encontrada significância estatística, evidenciando que a variável sexo teve efeito sobre os resultados. Conclui-se que a atratividade física é uma temática que deve ser problematizada no interior dos cursos de formaçáo (inicial ou continuada) para professores e outros profissionais, intentando melhores atendimentos, relacionamentos e percursos de ensino e aprendizagem para os alunos que são o público alvo da área de Educação Especial.
\end{abstract}

PALAVRAS-CHAVE: Educação Especial. Deficiências. Previsão de Resultados.

\begin{abstract}
This study aimed to determine whether the physical facial attractiveness of students with hearing impairment could influence the predictions of teachers who work in specialized educational services - Multifunction Resource Classrooms (MRCs). Twenty teachers who work in public municipal MRCs in a city of the state of São Paulo were selected. The participants carried out an activity involving the prediction of results for specialized educational services for students with hearing impairments. Photographs of children of both sexes, with different levels of physical attractiveness, were used as a stimulus. Favorable prognosis for specialized treatment was more frequently associated with students with high physical attractiveness. However, there were only statistically significant results for the photographs of girls, indicating that the gender variable had an effect on the results. We concluded that physical attractiveness is an issue that should be discussed in teacher development courses (undergraduate or continuing education) for teachers and other professionals, in order to improve treatment, relationships and teaching and learning pathways for students who are the target group of the field of Special Education.
\end{abstract}

KEYWORDS: Special Education. Disabilities. Prediction.

\footnotetext{
${ }^{1}$ Ao Prof. Sadao Omote, por disponibilizar o conjunto de fotografias obtidas a partir do estudo em que delineou um procedimento para avaliar a atratividade física facial de crianças com idade entre sete e 10 anos (OMOTE, 1991a).

Ao Prof Bruno Brandão Fischer, pela valiosa contribuição na análise dos dados desta pesquisa.

${ }^{2}$ Mestre e Doutorando em Educação Especial pela Universidade Federal de São Carlos. Endereço: Rua Osvaldo Pongetti, 313 , Centro, Nova Europa - SP, Brasil, CEP: 14920-000. evertongalera@hotmail.com

${ }^{3}$ Doutora em Psicologia pelo Instituto de Psicologia da Universidade de Sáo Paulo, docente do Departamento de Psicologia e do Programa de Pós-Graduação em Educação Especial da UFSCar. Endereço: Programa de Pós-Graduação em Educação Especial (PPGEEs), Centro de Educação e Ciências Humanas, Universidade Federal de São Carlos (UFSCar), Rodovia Washington Luís, Km 235, São Carlos - SP, Brasil, CEP: 13565-905. egmendes@ufscar.br
} 


\section{INTRODUÇÃo}

As deficiências e deformidades físicas quase sempre são visíveis e constantemente apreendidas pela coletividade como definidoras de estereótipos de feiura, materializando imperfeiçóes que promovem um conflito não camuflável na dinâmica das relaçóes interpessoais e sociais (AMARAL, 1988, 1995; OMOTE, 1990; QUEIROZ; OTTA, 2000). Mediante tal fenômeno, corrobora-se para que as pessoas com deficiência(s) apresente/m dificuldades no estabelecimento de vínculos afetivos e amorosos, contatos e/ou relacionamentos iniciais, dentre outros fatores, pela sua geometria anormal/disforme, por ser um corpo "desviante" (OMOTE, 2004).

As emoçóes pulsam e conduzem toda e qualquer interação social e, portanto, expressam todos os sentimentos, preconceitos, valores e intencionalidades construídas cultural e historicamente (AMARAL, 1994). Ao analisar os preconceitos e estigmas impostos à condição de deficiência/diferança, Amaral (2001) identificou, por exemplo, em obras literárias, a expressão de pensamentos e valores que podem agir como mecanismos de validadaçáo e naturalização dos processos de subjetivação e discriminação dos deficientes. Em um trecho do livro "Memórias Póstumas de Brás Cubas", de autoria de Machado de Assis, Amaral (2001, p.157) revela uma significativa associação entre a beleza e a deficiência pintada pelo autor, quando destaca no capítulo XXXIII:

O pior é que era coxa. Uns olhos tão lúcidos, uma boca tão fresca, uma postura tấo senhoril: e coxa! Esse contraste faria suspeitar que a natureza é às vezes um imenso escárnio. Por que bonita, se coxa? Por que coxa, se bonita? (...) e eu sem acudir a coisa nenhuma, elevado ao pé da minha Vênus Manca.

Atenta-se, então, para o fato de muitas pessoas ficarem perplexas ao encontrar pessoas com deficiências que não apresentam deformidades visíveis ou feiura aparente. Sobre a pessoa com deficiências recaem estigmas e estereótipos que promovem e reforçam o seu distanciamento de características, virtuosismos e performances comumente associadas às pessoas enquadradas nos padróes de beleza e atratividade física forjados cultural, social e historicamente (OMOTE, 1993).

Rosenthal e Jacobson (1973) trouxeram contribuiçóes valiosas para as pesquisas sobre estereótipos, mostrando que o sucesso/fracasso tem relação direta com as expectativas depositadas sobre as pessoas. Ao simular a aplicação de um teste de QI, os pesquisadores entregaram aos professores uma lista de alunos que supostamente teriam maiores chances de "sucesso" escolar. As expectativas positivas depositadas pelos professores, traduzidas em mais entusiasmo e motivaçáo para ensinar esses "alunos especiais", colocaram a profecia autorrealizadora em ação. Ao final do ano letivo os estudantes com o nome na lista mostraram, em média, um aumento de mais de 12 pontos em seus QIs, diferenciando-se da média das outras crianças que foi de 8 pontos.

Evidencia-se assim, que as percepçóes, projeçóes e previsóes iniciais forjadas sobre outrem, tenderiam a se concretizar. Desta feita, a beleza reflete um importante contexto para a investigação deste fenômeno, pois as pessoas percebidas como atraentes desenvolveriam qualidades desejáveis em resposta às expectativas de outras pessoas/grupos/sociedade (OMOTE, 1990, 1991, 1997; LEE-MANOEL et al., 2002). 
O trabalho de Rosenthal e Jacobson (1973) originou o modelo da expectativa, base conceitual que tem sido proposta para explicar as diferenças nos julgamentos dirigidos às pessoas atraentes e não atraentes. As expectativas formadas a partir de estereótipos ocorrem automaticamente, sem reflexão e sob o efeito da máxima "o bonito é bom", imprimindo características socialmente desejáveis às pessoas atraentes (BORDIERI; SOTOLONGO; WILSON, 1983; OMOTE, 1991b; LEE-MANOEL et al., 2002).

Ao longo dos tempos, alguns estudos têm demonstrado que as impressóes e expectativas de professores e outros profissionais, cunhados a partir de estereótipos orientados pela aparência/atratividade física podem ser decisivos no desenvolvimento e "sucesso" dos alunos. Crianças reconhecidas e/ou consideradas atraentes, comumente, são vistas como socialmente mais competentes e com maior potencial intelectual e acadêmico (CLIFFORD; WALSTER, 1973; KENEALY; FRUDE; SHAW, 1988; KNAPP; HALL, 1999).

Salvia, Algozzine e Sheare (1977) também investigaram a relação entre a atratividade física e desempenho acadêmico dos alunos em face dos julgamentos e expectativas dos professores. Foram selecionadas 84 crianças, de ambos os sexos, matriculadas em $3^{\mathrm{a}}, 4^{\mathrm{a}}$ e $5^{\mathrm{a}}$ séries de uma escola da Pensilvânia. Para a amostra final, foram escolhidas as sete crianças mais atraentes e as sete menos atraentes. Ao analisar as notas contidas no relatório escolar final, observou-se que as crianças atraentes tinham notas melhores e/ou superiores quando comparadas às crianças menos atraentes.

Omote (1990, 1991a, 1991b, 1993, 1993/94, 1997, 1999) ao direcionar seu foco analítico para uma investigação epistemológica centrada na atratividade física ${ }^{4}$ e a relação estreita com percepçóes, estereótipos e relações interpessoais no contexto da Educação Especial, contribuiu para a compreensão da realidade vivida e experimentada pelas pessoas com deficiências.

A partir dos estudos do autor supracitado compreender-se-á que uma pessoa com baixa atratividade física facial (AFF) pode ser identificada como possuindo menor competência acadêmica, intelectual e social (OMOTE, 1990, 1993), apresentando determinadas deficiências (OMOTE, 1993/94) e possuindo características negativas, comportamentos desviantes e outras desvantagens ou "desvirtudes" (OMOTE, 1991b).

Para investigar os efeitos da atratividade física sobre os julgamentos de profissionais, Elovitz e Salvia (1982) entregaram laudos (fictícios) acompanhados de fotografias e de nove perguntas para 324 psicólogos escolares. Os resultados apontaram que as indicaçóes para ocupar classes especiais para alunos com deficiência mental recaíram sobre as crianças com baixa atratividade física. Corroborando com um estudo anterior (ROSS; SALVIA, 1975) que demonstrou que os professores ao se depararem com relatórios (acompanhados de fotografias de menino ou menina, atraente ou náo) de alunos com desempenho escolar baixo e tendo que indicar aqueles que deveriam ser encaminhados para salas especiais para deficientes mentais, fizeram essa opção com mais frequência para os alunos não atraentes.

Omote (1997) com o propósito de verificar a relação entre a AFF de crianças encaminhadas a um tratamento especializado e a previsão de resultados, selecionou estudantes

\footnotetext{
${ }^{4} \mathrm{~A}$ atratividade física congrega inúmeros segmentos corporais; contudo, as referências sobre atratividade física neste estudo terão como elemento centralizador a face, ou seja, a atratividade física facial.
} 
do curso de pedagogia e fonoaudiologia. A tarefa a ser realizada consistia em examinar as fotografias de três crianças (de atratividade alta (AA), média (AM) e baixa (AB)), de ambos os sexos, indicando aquela que teria melhor resultado no tratamento fonoaudiológico. Os resultados apontaram que os prognósticos favoráveis recaíram mais frequentemente sobre as crianças com alta atratividade.

Ao pensar no processo de inclusão escolar enquanto uma caminhada que promova acesso a uma educação de qualidade para todos os educandos (OMOTE, 2004, 2006; CARVALHO, 2008; PACHECO et al., 2007; HEREDERO, 2010) e tendo por intençóes precípuas os avanços no que tange a construção de uma nova (melhor/outra) ordem social, política, econômica e ética, faz-se urgente, dentre outras necessidades, prover uma mudança paradgmática que interfira no convívio e aceitação das pessoas com deficiencias no ambiente social, cultural e escolar, modificando as expectativas e projeçóes construidas pelos professores/profissionais/especialistas, contribuindo para o atual (mas não recente) processo de inclusão escolar.

O debate sobre educação inclusiva no país tem alimentado muito mais os "fenômenos de retórica" do que contribuído efetivamente para a consolidação de uma educação de qualidade para a população alvo da Educação Especial. Neste sentido, tem se fortalecido um processo dual, congregando de um lado um sistema com estruturas coloridas pelo assistencialismo filantrópico e financiado por setores do poder público e, do outro, um sistema educacional esfacelado e frágil, incitado a acolher e assistir a escolarização desta parcela da população (MENDES, 2010a).

As Salas de Recursos Multifuncionais (SRMs), implantadas a partir de 2005, passaram a oferecer atendimento especializado aos alunos com deficiências, transtornos globais do desenvolvimento e altas habilidades/superdotação (MILANESI, 2012). No entanto, as salas de recursos e o atendimento educacional especializado (AEE) oferecido, mesmo representando um avanço nas políticas públicas voltadas à escolarização destes alunos, atendendo suas necessidades sem que precisem interromper sua trajetória escolar em salas comuns, por serem organizadas segundo um modelo/padrão não tem atendido com esmero às especificidades e necessidades que emanam da realidade social, familiar e histórica de cada aluno (MENDES, 2009, 2010b).

Para Omote (1997) os atuais discursos modificaram a forma de encarar diagnósticos e o funcionamento das deficiências, a ideia sobre a escolarização dos deficientes e os encaminhamentos e resultados do atendimento educacional especializado, apontando para a natureza biopsicossocial da deficiência, admitindo-se que além dos atributos anatômicos, fisiológicos e psicológicos do deficiente, deve-se considerar também o contexto das relações sociais e interpessoais onde está inserido.

Ao admitir que os níveis de atratividade física possam estruturar o percurso escolar e acadêmico de alunos em face das expectativas forjadas por professores e outros profissionais (CLIFFORD; WALSTER, 1973; SALVIA; ALGOZZINE; SHEARE, 1977; ELOVITZ; SALVIA, 1982; KENEALY; FRUDE; SHAW, 1988; LEE-MANOEL et al., 2002), deve-se pensar também como esta realidade se apresenta para os alunos com deficiências, apreendidos histórica e culturalmente como pessoas não atraentes ou feias (AMARAL, 1988, 1995), colaborando com os estudos e discussóes acerca da realidade social, política e educacional envolvendo as pessoas com deficiências. 
Considerando a importância do AEE para a escolarização e desenvolvimento integral de alunos com deficiências, faz-se necessário compreender se a atratividade física facial destes alunos poderia (ou não) influenciar também nas expectativas dos professores que atuam em Salas de Recursos Multifuncionais. Portanto, o presente estudo intencionou um caminho analíticoreflexivo para investigar o possível impacto exercido pela atratividade física facial de alunos com deficiências sobre os prognósticos realizados por professores que atuam na educação especial.

Segundo Omote (1993) a AFF pode estar exercendo influência decisiva na vida de pessoas com deficiências, desde a suspeita inicial da deficiência em um aluno até o tratamento destinado a cada um, assim como para avaliaçóes, prognósticos e encaminhamentos a algum tipo de serviço especializado.

Diante do exposto, o presente estudo objetivou verificar a relação entre a atratividade física facial e o prognóstico feito por professores que atuam no atendimento educacional especializado - "Salas de Recursos Multifuncionais" - para alunos com deficiências, transtornos globais do desenvolvimento e altas habilidades/superdotação.

\section{Método}

Este estudo é de caráter quantitativo e de cunho descritivo, do tipo transversal, intentando por meio de seus procedimentos teóricos e metodológicos, apresentar e descrever a relação entre atratatividade física e o prognóstico para o atendimento educacional especializado de crianças com deficiências.

Os estudos descritivos têm por preocupação apresentar o quadro panoramico sobre o estado de uma ou mais variáveis para pessoas, grupos ou objetos especificos, representando o que poderiamos compreender como sendo a "fotografia" de um acontecimento, fenômeno, situação ou objeto capturado em um tempo/espaço definido (SAMPIERI; COLLADO; LUCIO, 2006).

\subsection{Participantes}

Com o propósito de selecionar os participantes, realizou-se um mapeamento junto a um município do interior do estado de São Paulo. O referido município integra as açóes de um projeto de pesquisa intitulado "Observatório nacional de educação especial: estudo em rede nacional sobre as salas de recursos multifuncionais nas escolas comuns" 5 , tendo como principal objetivo a criação de uma rede de cooperação e troca de experiências entre pesquisadores da área de Educação Especial, promovendo avanços ciêntíficos, sociais e políticos direcionados aos sistemas educacionnais brasileiros. Neste momento, faz-se relevante destacar que o presente estudo é parte integrante de uma pesquisa maior do Observatório Nacional de Educação Especial (Oneesp).

Foram identificados todos os professores do município que atuam em SRMs, contabilizando um total de vinte e cinco professores (distribuídos entre 17 escolas e um Centro de AEE). Para selecionar os participantes admitiram-se como critérios de inclusão:

\footnotetext{
${ }^{5}$ Criado a partir da aprovação do projeto "Fomento às açóes do PPGEES da UFSCAR em redes de cooperação científica sobre educação inclusiva”, do Programa de Pós-Graduação em Educação Especial.
} 
a) ter disponibilidade e interesse em colaborar e/ou participar do estudo; b) atender alunos com deficiências que estejam matriculados no ensino regular; c) assinatura do Termo de Consentimento Livre e Esclarecido (TCLE).

Foram selecionados vinte professores que atuavam em SRMs (distribuídas por 13 escolas e um Centro de AEE) atendendo alunos com deficiências (matriculados no ensino regular). Suas identidades foram preservadas utilizando-se letras (A, B, C, D, E, F...) para definir cada um deles.

O estudo foi submetido e aprovado pelo Comitê de Ética em Pesquisa em Seres Humanos da UFSCar sob o Parecer no 174.748, em dezembro de 2012, estando em conformidade com a Resolução no 196, que trata das Diretrizes e Normas Regulamentadoras de Pesquisas Envolvendo Seres Humanos (BRASIL, 1996).

\subsection{INSTRUMENTOS}

Formulário para caracterização dos professores de salas multifuncionais ou de recursos $^{6}$. O preenchimento do formulário possibilitou a caracterização dos participantes, fornecendo informações sobre formação inicial e continuada, tempo de serviço na área de Educação Especial, clientela atendida e outras.

Termo de Concentimento Livre e Esclarecido.

Seleção de trinta fotografias (em preto e branco) com diferentes níveis de atratividade, sendo 15 de meninas (cinco de AA, cinco de AM e cinco de $\mathrm{AB}$ ) e 15 de meninos (divididas também em AA, AM e AB). Estas fotografias foram selecionadas a partir de um estudo onde foi delineado um procedimento para avaliar a atratividade física facial (AFF) de crianças com idade cronológica entre sete e 10 anos (OMOTE, 1991a). A eficiência destas fotografias como estímulo para trabalhos/estudos envolvendo AFF foi demonstrada posteriormente (OMOTE, 1991b). Ademais, outro estudo demonstrou a estabilidade temporal e a possibilidade de generalização para o julgamento dos níveis de atratividade das fotografias (OMOTE, 1994).

\subsubsection{SeleÇáo das Fotografias UTILIZADAS COMO ESTÍMULO}

O material cunhado por Omote (1991a) reúne uma quantidade expressiva de fotografias, que por sua vez, permitem a formação de inúmeras combinaçóes. Ao pensar que o teste a ser aplicado com os professores das SRMs requeriria apenas dois conjuntos de fotografias (um de meninas e outro de meninos) com diferentes níveis de atratividade para cada (AA, AM e $\mathrm{AB}$ ), constatou-se que não seria possível utilizar todas as fotografias, já que o número de participantes seria insuficiente perante a quantidade de combinaçóes possíveis.

Desta feita, optou-se pela realização de um "teste piloto das fotografias" envolvendo três etapas: a) tratamento das fotografias em estúdio fotográfico, mantendo-se as características originais; b) revelação/impressão das fotografias em tamanho $7 \times 10 \mathrm{~cm}$; c) utilização de juízes para escolher, dentre todas as fotografias, apenas uma para representar cada nível de

\footnotetext{
${ }^{6}$ Este formulário de caracterizaçáo integra o volume de instrumentos desenvolvidos e utilizados pelo Observatório Nacional de Educação Especial (Oneesp).
} 
atratividade. Deste procedimento, foram selecionadas seis fotografias (meninos de alta, média e baixa atratividade e meninas de alta, média e baixa atratividade) para servirem como estímulo de AFF durante a realização dos procedimentos de coleta.

\subsection{Procedimentos DA PESQUisa}

Foi realizado contato com a Secretaria Municipal de Educação intuindo conseguir permissão para a realização do estudo. Em seguida, os professores que atuam nas SRMs foram contactados e uma visita para apresentar o estudo e esclarecer possíveis dúvidas foi agendada. Quando consentia sua participação, o professor assinava o TCLE e acordava data para a realização do teste. Neste momento, era salientado que o teste consistiria na realização de uma tarefa sobre prognóstico para o atendimento educacional especializado de alunos com deficiências.

Neste interim, foi realizado um teste piloto ansiando obter um material de qualidade para o estudo principal. Então, o teste foi organizado e aplicado, tendo como juízes professores do ensino básico da rede pública estadual, permitindo visualizar e sanar as dificuldades e problemas advindos da sua aplicaçáo, entendimento e execução.

Os professores realizaram as tarefas individualmente, em encontros que ocorreram nas escolas (13) ou no centro especializado em que atuavam junto às SRMs. Durante o encontro, o participante, inicialmente, preenchia o formulário de caracterização e recebia uma folha contendo o convite para participar de uma pesquisa sobre prognósticos para o atendimento educacional especializado e as instruçóes sobre o teste a ser realizado. Nesta folha, era informado que receberia as fotografias de três crianças com déficits moderados de audição e que, em decorrência deste quadro, apresentavam alteraçóes significativas na linguagem/comunicação oral. Ainda, era explicitado que essas crianças recebiam atendimento educacional especializado e o teste a ser realizado consistiria em examinar as fotografias e indicar a criança que teria os melhores resultados perante o atendimento em SRMs.

Em seguida, este material era recolhido e entregue uma folha contendo as fotografias de três meninos ou de três meninas com diferentes níveis de atratividade (sendo uma fotografia de $\mathrm{AA}$, uma fotografia de $\mathrm{AM}$ e outra de $\mathrm{AB}$ ) e solicitado que observasse as fotografias e marcasse com um " $\mathrm{x}$ " a criança que teria maior progresso no atendimento educacional especializado. Então, o material era novamente recolhido e entregue outra folha (agora contendo fotografias de crianças do sexo oposto), permitindo que o procedimento realizado anteriormente se repetisse.

Os dados coletados foram organizados e analisados quantitativamente, utilizando-se procedimentos estatísticos que permitiram identificar a relação entre os níveis de AFF de alunos com deficiência auditiva e a previsão de resultados favoráveis para o atendimento educacional especializado. Optou-se pelo uso de análises estatísticas não paramétricas com a finalidade de analisar as diferenças estatísticas entre os grupos AA-AM, AA-AB e AM-AB, tanto para as fotografias das meninas quanto para as fotografias dos meninos. 


\section{Resultados}

\subsection{CARACTERIZAÇÁO dOS PARTICIPANTES}

Embora náo trate do escopo do estudo analisar, discutir e refletir acerca do perfil profissional e acadêmico dos professores que atuam nas SRMs, oferendo atendimento especializado para alunos com deficiências, transtornos globais do desenvolvimento e altas habilidades/superdotação, dar-se-á destaque para algumas particularidades que podem ajudam a traçar um quadro geral sobre o AEE neste município.

É possível observar, partindo do exame da Tabela 1, que todos os participantes são do sexo feminino com média de 39 anos de idade. O fato de apresentarem formaçáo em nível superior e possuírem ao menos quatro anos de experiência na área de Educação Especial sinaliza, mesmo aceitando todo o tipo de relativismo, que possuem uma formaçáo e experiência (ao menos mínima) adequada para atuar em SRMs.

Todos os professores possuem habilitaçáo em Educaçáo Especial e metade avançou a outros níveis de formação, como especialização, mestrado ou doutorado. Ao examinar a Tabela 1 observa-se também que, na visão da maioria dos participantes, encontrar-se-ấo condiçóes adequadas de trabalho junto às salas de recursos multifuncionais, excetuando-se três participantes que afirmaram não exercer suas atividades e práticas didático-pedagógicas em salas equipadas e outros três que afirmaram que as salas estavam instaladas em locais inadequados na escola.

Tabela 1- Caracterização dos professores de salas multifuncionais ou de recursos

\begin{tabular}{cccccccccc}
\hline Sujeitos & Sexo & Idade & $\begin{array}{c}\text { Nível de } \\
\text { Formação }\end{array}$ & $\begin{array}{c}\text { Exp. } \\
\text { Ed.Esp. } \\
\text { (anos) }\end{array}$ & $\begin{array}{c}\text { Exp. } \\
\text { AEE } \\
(\operatorname{anos})\end{array}$ & $\begin{array}{c}\text { Formação em } \\
\text { Ed.Esp. }\end{array}$ & $\begin{array}{c}\text { Qtde } \\
\text { Aluno }\end{array}$ & $\begin{array}{c}\text { SRM } \\
\text { Equipa- } \\
\text { das }\end{array}$ & $\begin{array}{c}\text { SRM } \\
\text { Local } \\
\text { Ade- } \\
\text { quado }\end{array}$ \\
\hline A & F & 41 & Superior & 17 & 5 & Habilit./Espec. & 17 & Sim & Sim \\
B & F & 43 & Superior & 17 & 3 & Habilitação & 9 & Sim & Sim \\
C & F & 58 & Superior/Magist. & 17 & 2 & Habilitação & 12 & Sim & Sim \\
D & F & 43 & Superior & 17 & 3 & Habilitação & 11 & Sim & Sim \\
E & F & 28 & Superior & 4 & 2 & Habilit./Espec. & 34 & Sim & Sim \\
F & F & 39 & Superior & 13 & 5 & Habilit./Mestr./ & 32 & Não & Sim \\
G & F & 37 & Superior & 13 & 5 & Habilit./Espec. & 12 & Sim & Sim \\
H & F & 29 & Superior & 4 & 4 & Habilitação & 18 & Sim & Sim \\
I & F & 31 & Superior/Magist. & 5 & 0,5 & Habilit./Mes.* & 43 & Sim & Sim \\
J & F & 41 & Superior & 7 & 7 & Habilitação & 4 & Sim & Sim \\
L & F & 47 & Superior/Magist. & 16 & 3 & Habilitação & 10 & Sim & Sim \\
M & F & 42 & Superior & 7 & 2 & Habilit./Espec. & 15 & Sim & Não \\
N & F & 32 & Superior & 8 & 8 & Habilit./Espec. & 19 & Não & Não \\
O & F & 44 & Superior & 25 & 3 & Habilitação & 1 & Sim & Sim \\
P & F & 46 & Superior/Magist. & 6 & 6 & Habilitação & 28 & Sim & Sim \\
Q & F & 41 & Superior/Magist. & 16 & 11 & Habilit./Mestr.e & 11 & Sim & Sim
\end{tabular}




\begin{tabular}{cccccccccc} 
R & F & 31 & Superior & 2,5 & 1 & Habilit./Espec. ${ }^{*} /$ & 16 & Sim & Sim \\
S & F & 46 & Superior/Magist. & 20 & 4 & Habilitação & 10 & Sim & Sim \\
T & F & 40 & Superior/Magist. & 17 & 4 & Habilitação & 20 & Não & Não \\
U & F & 33 & Superior & 9 & 9 & Habilit./Espec. & 15 & Sim & Sim \\
\hline
\end{tabular}

*Representa formação em outras áreas de atuação e/ou especialidade acadêmico-profissional.

Fonte: Elaboração dos autores

\subsection{ATRATIVIdAdE Física FACIAL E A DEFINIÇÃo dOS PROGNÓSTICOS}

Ao término da aplicação do teste, cada participante escolheu a fotografia de um menino e de uma menina como sendo os alunos que teriam melhores resultados ao final do atendimento educacional especializado. Os resultados obtidos a partir desta etapa foram organizados e descritos em Tabelas, onde é possível verificar a frequência com que cada fotografia, com diferentes níveis de atratividade física facial, foi escolhida para cada sexo e as decorrentes análises estatísticas.

Os resultados obtidos com o teste One-Sample Kolmogorov-Smirnov Test, revelam que o nível de significância assintótica bi-caudal da distribuição das indicaçôes de acordo com níveis de atratividade física facial $(\mathrm{AA}, \mathrm{AM}$ e $\mathrm{AB})$ não ocorre em padrão de normalidade tanto para as meninas quanto para os meninos. Justifica-se assim a utilizaçáo de análises estatisticas não paramétricas que indiquem a existência (ou não) de significância estatística relevante, já que as escolhas dos alunos que obteriam maior progresso no atendimento educacional especializado náo recaíu igualmente sobre as fotografias de meninos e meninas com diferentes níveis de atratividade física facial.

Ao verificar a Tabela 2 constata-se que a maior incidência de escolhas e/ou indicaçóes acerca dos alunos que teriam possivelmente os resultados mais favoráveis no decorrer do atendimento educacional especializado e, desta feita, o melhor prognóstico para o AEE, voltouse para aqueles com atratividade alta (AA), seguidos daqueles com atratividade média (AM) e, por último, recebendo poucas indicaçóes estão os alunos com atratividade baixa (AB).

Tabela 2- Descrição da frequência de escolhas dos alunos que teriam o melhor prognóstico para o atendimento educacional especializado.

\begin{tabular}{lcccc}
\hline \multicolumn{2}{c}{ MENINOS } & \multicolumn{2}{c}{ MENINAS } \\
\hline AFF & N Observado & N Esperado & N Observado & N Esperado \\
\hline AB & $3 \mathrm{c}$ & 6,67 & $4 \mathrm{a}$ & 6,67 \\
\hline $\mathrm{AM}$ & $8 \mathrm{c}$ & 6,67 & $4 \mathrm{a}$ & 6,67 \\
\hline $\mathrm{AA}$ & $9 \mathrm{c}$ & 6,67 & $12 \mathrm{~b}$ & 6,67 \\
\hline Total & 20 & & 20 & \\
\hline
\end{tabular}

As letras minúsculas possibilitam comparaçóes nas colunas. Valores seguidos de letras iguais não diferem estatisticamente entre si.

$\mathrm{a}=\mathrm{p}>0,05$

$\mathrm{b}=\mathrm{p}<0,05$

$\mathrm{c}=\mathrm{p}>0,05$

Fonte: Elaboração dos autores 
Os testes qui-quadrado realizados para os meninos e as meninas demonstram que com base nos valores previstos (esperados) e observados, é possível notar somente para o caso das fotografias de meninas uma significância estatística relevante $(\mathrm{p}=0,041)$, permitindo identificar uma maior tendência de escolha de alunas do grupo de atratividade alta (AA) em detrimento daquelas dos grupos de atratividade média (AM) e atratividade baixa (AB). Estatisticamente, esta hipótese náo se confirma para as fotografias dos meninos ( $p=0,212)$, o que se deve a uma distribuição aproximada nas escolhas para os grupos de média e alta atratividade, reduzindo a capacidade da amostra de exibir uma tendência clara neste sentido.

Portanto, embora a previsão de resultados para o atendimento educacional especializado indique que os prognósticos favoráveis recaíram mais frequentemente sobre os alunos com alta atratividade, o efeito dos diferentes níveis de atratividade física foi estatisticamente significante apenas para as fotografias das meninas, sinalizando que o sexo ao qual pertencia o aluno da fotografia produziu efeitos diferenciados sobre os julgamentos dos professores de SRMs.

Outro resultado interessante e que não estava previsto no escopo do estudo referese à análise feita para investigar se o tempo de experiência na área de Educação Especial poderia influenciar no prognóstico para o atendimento educacional especializado. Testes nãoparamétricos foram realizados usando o tempo de experiência em educação especial como variável de agrupamento. A partir da Tabela 3 nota-se que não há diferença estatisticamente significativa para a escolha dos alunos que teriam melhores prognósticos, utilizando como parâmetro este tempo de experiência. Nota: $\mathrm{O}$ tempo de experiência dos professores foi agrupado em dois construtos: a) até 10 anos e b) mais de 10 anos.

Tabela 3- Estatísticas não-paramétricas para diferenças entre grupos (Agrupamento por tempo de experiência em Educação Especial)

\begin{tabular}{lcc}
\hline & MENINOS & MENINAS \\
\hline Mann-Whitney U & 42,5 & 45,5 \\
Wilcoxon W & 87,5 & 111,5 \\
Z & $-0,579016327$ & $-0,346337256$ \\
Asymp. Sig. (2-tailed) & 0,563 & 0,729 \\
Exact Sig. [2*(1-tailed Sig.)] & 0,603 & 0,766 \\
\hline
\end{tabular}

Fonte: Elaboração dos autores

Esta pode ser uma evidência para a suposição de que a experiência profissional não ofereceria as condiçóes significativas e/ou vivências adequadas para neutralizar a força dos estereótipos criados a partir da atratividade física facial dos alunos.

\section{DiscussốES}

O presente estudo aponta na direção da suposição de que o efeito do estereótipo envolvendo a atratividade física não foi tão decisivo no momento em que os professores tiveram que selecionar os alunos que teriam maior/melhor progresso no atendimento educacional 
especializado. Em concordância com Eagly et al. (1991) que desenvolveram um estudo de metaanálise destacando que a força da atratividade física sobre os julgamentos e expectativas não seria universal e tão intensa como advogam inúmeras pesquisas sobre estereótipos, tratando-se sempre de uma questão relativa e suscetível a inúmeras circunstâncias e fatores.

A relação entre os diferentes níveis de atratividade física e a previsão de resultados para o atendimento educacional especializado obteve significância estatística apenas para as fotografias de meninas, já que para os meninos houve a definição de prognósticos favoráveis em maior quantidade para as fotografias de atratividade alta, seguidas das fotografias de média e baixa atratividade, mas essa diferença não demonstrou significância estatística.

Destarte, os níveis de atratividade das fotografias dos meninos e a sua relação com a previsão de resultados favoráveis para o AEE não apresentaram significância estatística. Portanto, os resultados não apontam integralmente na direção dos achados de Bordieri, Sotolongo e Wilson (1983) e Omote (1997), nos quais a variável (AFF) influênciou, respectivamente, nos prognósticos favoráveis para a reabilitação de pessoas paraplégicas e para o atendimento especializado para pessoas com surdez.

A utilização de poucas fotografias como estímulo para a realização do estudo, traduzindo-se em apenas três para os meninos e três para as meninas, selecionadas a partir de um "teste piloto das fotografias", talvez possa ter colaborado para o estabelecimento de alguma tendenciosidade alavancada por características ou componentes de alguma face em particular.

A possibilidade de uma ocorrência desta natureza já havia sido considerada nos estudos de Omot1 (1991b, 1993/94, 1997). Essa tendenciosidade perante algumas fotografias pode ser destacada para ajudar a explicar a diferença obtida na previsão de resultados para os meninos, já que os prognósticos favoráveis racaíram de maneira similar sobre os meninos de média e alta atratividade física.

Para Omote (1999) alguns elementos da face desempenham importante papel na caracterização da atratividade física facial, de maneira que os olhos, boca, nariz e cabelo podem, isoladamente, caracterizar uma face como atraente ou náo. Como o presente estudo utilizou apenas uma fotografia para cada nível de AFF, para ambos os sexos, a suscetibilidade a este tipo de interferência foi alta e não pode ser descartada.

Os resultados também não se aproximam de outros estudos encontrados na literatura, para os quais a variável sexo não promoveu alteraçôes perante os resultados obtidos nas pesquisas que intuíam investigar a importância da atratividade física nos julgamentos e expectativas cunhadas por professores e outros profissionais (ELOVITZ; SALVIA, 1982; OMOTE, 1991b, 1993/94, 1997).

Como já destacado, a análise dos resultados também permitiu observar que a experiência dos professores na área de Educação Especial não foi suficiente para evitar que os diferentes níveis de atratividade das fotografias exercessem impacto na previsão de resultados para o atendimento educacional especializado. Outros estudos realizados com professores e psicólogos (CLIFFORD; WALSTER, 1973; ROSS; SALVIA, 1975; SALVIA; ALGOZZINE; SHEARE, 1977; ELOVITZ; SALVIA, 1982; KENEALY; FRUDE; SHAW, 1988), também evidenciaram que a experiência profissional não foi suficiente para impedir que a atratividade 
física facial dos alunos tivesse efeito na atribuição de qualidades, comportamentos e expectativas que recaíam sobre eles.

Durante a realização dos testes, embora não tenha destinado espaço próprio para esta investigação, foi possível se deparar com várias situaçôes em que os participantes perguntavam se uma das crianças (sempre aquela de atratividade baixa) não possuía também uma deficiência intelectual, além daquela já anunciada no teste. Esta realidade coaduna com outros estudos que demonstraram que a baixa atratividade física pode favorecer a identificação/atribuição de algumas deficiências, favorecendo o encaminhamento de crianças para serviços de atendimento especializado, tanto por parte do professor (ROSS; SALVIA, 1975) quanto por indicação do psicólogo escolar (ELOVITZ; SALVIA, 1982), com destaque para o fato de que alunos com baixa atratividade são encaminhados, em geral, para a classe especial destinada a deficientes mentais ${ }^{7}$. A forte associação entre baixa atratividade física e deficiência mental também foi demonstrada por Omote (1993, 1993/94).

Neste sentido, encontra-se também uma aproximação com estudos que identificaram a estreita relação entre baixa atratividade física e as avaliações e expectativas desfavoráveis acerca da competência intelectual/acadêmica/social dos alunos (KNAPP; HALL, 1999; CLIFFORD; WALSTER, 1973; KENEALY; FRUDE; SHAW, 1988). Contudo, Salvia, Algozzine e Sheare (1977) propóem estudar o fenômeno durante longo prazo para observar se a relação professor/ aluno pode ser alterada, no tocante às percepçóes sobre o desempenho acadêmico, intelectual e socais dos educandos.

Nesta perspectiva, a familiaridade também pode ser determinante no processo de avaliação da atratividade física, tanto para professores perante seus alunos (SALVIA; ALGOZZINE; SHEARE, 1977) quanto para crianças perante seus colegas (LEE-MANOEL et al., 2002), podendo (ou não) ocorrer a permanência dos estereótipos na atribuição de expectativas, características e resultados.

Mesmo considerando que tanto os estudos que partiram de situaçóes e casos fictícios quanto para aqueles que propuseram investigaçóes em espaços e práticas sociais reais, a atratividade física exerceu influência nos julgamentos e avaliaçóes de diferentes aspectos dos alunos (OMOTE, 1990), a escolha dos próprios alunos dos professores de SRMs como estímulo permitiria analisar se, como destaca Lee-Manoel et al. (2002), o efeito do estereótipo torna-se menor à medida que aumenta o grau de informação sobre a pessoa que está sendo julgada.

\section{Conclusótes}

O estudo pode responder ao objetivo pretendido ao verificar que há relação estreita entre a atratividade física facial e o prognóstico feito por professores que atuam nas salas de recursos multifuncionais com a oferta do atendimento educacional especializado.

Portanto, pode-se admitir que os professores de SRMs também estariam sujeitos às determinaçóes e processos subjetivos que tornam alguns estereótipos e preconceitos,

\footnotetext{
${ }^{7}$ A opçấo por utilizar a definição "deficiência metal" deve-se a escolha do pesquisador por manter um diálogo estreito com os autores e suas respectivas obras.
} 
particularmente, aqueles cunhados mediante a percepção e avaliação da atratividade física, definidores de expectativas positivas ou não para alunos com deficiências.

Intentando conhecer melhor o processo que possibilita atribuir determinadas características positivas às crianças mais atraentes, permitindo compreender e agir com o objetivo de reduzir os efeitos que tem os estereótipos na avaliação, nas atitudes e no comportamento dos alunos com deficiências, deve-se pensar também em pesquisas que possam partir da realidade concreta dos sujeitos e não apenas de situaçóes e/ou casos fictícios como o apresentado neste estudo.

Se os próprios alunos com deficiências, transtornos globais do desenvolvimento e altas habilidades/superdotação atendidos nas SRMs fossem considerados no estudo sobre atratividade física, poder-se-ia verificar não apenas se os melhores prognósticos recaem sobre os alunos mais atraentes, mas, invariavelmente, se possuiriam de fato melhor rendimento ou desempenho. Isto permitiria analisar se há diferenças (cognitivas, intelectuais, sociais, acadêmicas ou comportamentais) significativas entre os alunos avaliados como atraentes e não atraentes, evidenciando a ocorrência (ou nlapreende-se que as melhorias na educação, formação e ensino das pessoas com deficiências, transtornos globais do desenvolvimento e altas habilidades/superdotação passam pelas modificaçóes, transformaçóes e aperfeiçoamento das infraestruturas, materiais, procedimentos, serviços e atendimentos destinados a essa parcela da população e, invariavelmente, pela compreensão, análise e crítica de todos os processos, objetivaçóes e materialidades da produção humana.

O estudo também sinaliza para a importância de dar prosseguimento às investigaçóes e estudos sobre o tema da atratividade física, intentando diminuir os possíveis efeitos deletérios para a aprendizagem e para a vida daquelas pessoas com deficiências que são subjulgadas por sua condição de não atratividade.

\section{REFERÊNCIAS}

AMARAL, L. A. Do Olimpo ao mundo dos mortais. São Paulo: Edmetec, 1988. 1994. . Corpo Desviante/Olhar Perplexo. Revista Psicologia USP, São Paulo, v.5, n.1/2, p.245-268, . Conhecendo a deficiência (em companhia de Hércules). Robe Editorial: São Paulo, 1995. . A diferença corporal na literatura: um convite a segundas intençóes.

In: SILVA, S.; VIZIM, M. (Org.). Educaçâo Especial: múltiplas leituras e diferentes significados. Campinas: Mercado das Letras: Associação de Leitura do Brasil, 2001. p.131162.

BORDIERI, J. E.; SOTOLONGO, M.; WILSON, M. Physical attractiveness and attributions for disability. Rehabilitation Psychology, Washington, v.28, n.4, p.207-215, 1983.

CARVALHO, R. E. Escola inclusiva: a reorganização do trabalho pedagógico. Porto Alegre: Editora Mediação, 2008.

CLIFFORD, M. M.; WALSTER, E. The effect of physical attractiveness on teacher expectations. Sociology of Education, Washington, v.46, p.248-258, 1973. 
EAGLY, A. H. et al. What is beautiful is goog, but...: a meta-analytic review of research on the physical attractiveness stereotype. Psychological Bulletin, Washington, v.110, n.1, p.109-128, 1991.

ELOVITZ, G. P.; SALVIA, J. Attractiveness as a biasing factor in the judgments of school psychologists. Journal of School Psychology, New York, v.20, p.339-345, 1982.

HEREDERO, E. S. A escola inclusiva e estratégias para fazer frente a ela: as adaptaçóes curriculares. Acta Scientiarum Education, Maringá, v.32, n.2, p.193-208, 2010. Disponível em: < http://periodicos.uem.br/ojs/index.php/ActaSciEduc/article/viewArticle/9772 >. Acesso em: 20 abr. 2012.

KENEALY, P.; FRUDE, N.; SHAW, W. Influence of children's physical attractiveness on teacher expectation. Journal of Social Psychology, New York, v.128, p.373-383, 1988.

KNAPP, M. L.; HALL, J. A. Comunicação não-verbal na interação humana. Trad. M. A. L. Barros. São Paulo: JSN Editora, 1999. (Original publicado em 1972).

LEE-MANOEL, C. L. et al. Quem é Bom (e Eu Gosto) é Bonito: efeitos da familiaridade na percepção de atratividade física em pré-escolares. Psicologia: Refl. e Crít., Porto Alegre, v.15, n.2, p.271282, 2002.

MENDES, E. G. A formação do professor e a política de Educação Especial. In: SEMINÁRIO NACIONAL DE PESQUISA EM EDUCAÇÃO ESPECIAL: FORMAÇÃO DE PROFESSORES EM FOCO, 5., 2009, São Paulo. Anais... São Paulo, 2009. 1CD-ROM

. Breve histórico da Educação Especial no Brasil. Revista Educación y Pedagogía, Medellín, v.22, n.57, mayo-agosto, p.93-110, 2010a. Disponível em: <http://aprendeenlinea.udea.edu.co/revistas/ index.php/revistaeyp/article/viewFile/9842/9041>. Acesso em: 05 dez. 2012.

. Observatório Nacional de Educação Especial: estudo em rede nacional sobre as Salas de Recursos Multifuncionais nas escolas comuns. Projeto 039. São Carlos: UFSCar, 2010b.

MILANESI, J. B. Organização e funcionamento das salas de recursos multifuncionais em um município paulista. 2012. 183 f. Dissertação (Mestrado em Educação Especial) - Programa de Pós-Graduação da Universidade Federal de São Carlos, São Carlos, 2012.

OMOTE, S. Aparência e competência em Educacao Especial. Temas em Educação Especial, São Carlos, v.1, p.11-26, 1990.

Avaliação da atratividade física facial: delineamento de um procedimento. Psicologia: Teor. $e$ Pesq., Brasília, v.7, n.3, p.285-294, 1991a.

. Efeitos da atratividade física facial de crianças sobre a percepção de outras qualidades delas. Psicologia: Teor. e Pesq., Brasília, v.7, n.3, p.295-302, 1991 b.

. Estudos de atratividade física facial em Educação Especial. Temas em Educação Especial, São Carlos, v.2, p.273-282, 1993.

. Atratividade Física Facial e Percepção de Deficiências. Didática, São Paulo, v.29, n.1, p.115124, $1993 / 94$.

1997.

. Atratividade física facial e prognóstico. Psicologia: Teor. e Pesq., Brasília, v.13, n.1, p.113-117,

. Componentes da atratividade física facial. Cadernos da F.F.C., Marília, v.8, n.1, p.87-107,

1999. 
. Estigma no tempo da inclusão. Revista Brasileira de Educação Especial, Marília, v.10, n.3, p.287-308, set.-dez, 2004.

. Inclusão e a questão das diferenças na educação. Perspectiva, Florianópolis, v.24, p.251-272, 2006. Disponível em: <http://www.perspectiva.ufsc.br/perspectiva_2006_especial/13_Sadao.pdf >. Acesso em: 21 abr. 2012.

PACHECO, J. et al. Caminhos para a inclusão: um guia para o aprimoramento da equipe escolar. Porto Alegre: Artmed, 2007.

QUEIROZ, R.; OTTA, E. A beleza em foco: condicionantes culturais e psicobiológicos na definição da estética corporal. In: QUEIROZ, R. (Org.). O corpo do brasileiro: estudos de estética e beleza. 2. ed. São Paulo: Editora Senac, 2000. p.13-66.

ROSENTHAL, R.; JACOBSON, L. Expectativas de professors em relação a alunos pobres. In: HARDIN, G. J. A ciência social num mundo em crise. Trad. D.M. Leite. São Paulo: Perspectiva, 1973. p.199-205. (Original publicado em 1968).

ROSS, M. B.; SALVIA, J. Attractiveness as a biasing factor in the teacher judgments. American Journal of Mental Deficiency, Washington, v.80, p.96-98, 1975.

SALVIA, J.; ALGOZZINE, R.; SHEARE, J. B. Attractiveness and school achievement. Journal of School Psychology, Memphis, v.15, n.1, p. 60-67, 1977.

SAMPIERI, R. H.; COLlADO, C. H.; LUCIO, P. B. Metodologia de Pesquisa. 3. ed. São Paulo: McGraw-Hill, 2006.

Recebido em: 20/03/2013

Reformulado em: 29/09/2013

Aprovado em: 04/10/2013 
OLIVEIRA, E. L. \& MENDES, E. G. 